\title{
Adult Dental Patients With Avoidance Behaviours
}

\author{
Narges Farhad Mollashahi ${ }^{1, *}$ \\ ${ }^{1}$ Department of Endodontics, School of Dentistry, Zahedan University of Medical Sciences, Zahedan, IR Iran \\ ${ }^{*}$ Corresponding author: Narges Farhad Mollashahi, Department of Endodontics, School of Dentistry, Zahedan University of Medical Sciences, Zahedan, IR Iran. Tel: +98-5433414004, \\ E-mail: nargesfarhadm@gmail.com
}

Received: September 11, 2014; Revised: September 28, 2014; Accepted: October 9, 2014

Keywords:Dental Anxiety; Quality of Life; Oral Health

\section{Dear Editor,}

Fear is an adoptive human response in the face of danger. This normal and even useful reaction has a protective aspect, while phobia is a pathologic, irrational, and intense fear of a situation or an issue (1). Dental phobia or odontophobia is a pathologic fear that affects about $5 \%$ to $15 \%$ of adults in the industrialized countries (2).

Dental fear is a complex multidimensional phenomenon that its development involves a number of factors including personality traits, fear of pain, previous traumatic experiences (especially in childhood), anxious entourage, and blood-injury fear. Certain variables such as gender and education (socioeconomic status) are associated with anxiety level; therefore, women are more affected than men and the young more than the old. The people with low education and low income are more likely to have higher levels of fear experience $(1,3,4)$.

Fear is the main obstacle for routine dental treatment. Fear of pain is strongly associated with anxiety and avoidance of treatment that in turn is highly correlated with increased caries morbidity and DMFS scores (5). Kent believes that toothache memory is formed in time and severely anxious patients tend to overestimate their pain (6). Through a vicious cycle dynamic, fear of dental treatment can block normal access to health services, which increases the risk of experiencing oral diseases, and the progressive worsening of untreated oral symptoms can in turn reinforce the fear of dental procedures $(4,7,8)$. Since failing to see a physician, gingival problems and tooth decay progress day by day and destruction becomes more severe, the patient has inevitably to recourse and this is just the beginning of the problems. Under such circumstances, the dentist is faced with a situation that is very difficult to treat. In fact, the result of fear and lack of timely treatment is to tolerate more complex, expensive, and time consuming treatments with lower success rate (8).

In addition to the above effects, dental anxiety has much greater impacts on quality of life. Cognitive effects include negative thoughts, fear, crying, sleep disturbances, disturbed eating, habits, and greater self-medication (1). Helping highly anxious patients to overcome their fear of dental treatment is a challenge, however if achieved it will result in improvement of their oral health, their overall quality of life, and well-being (1).

\section{References}

1. Hmud R, Walsh LJ. Dental anxiety: causes, complications and management approaches. J Minim Interv Dent. 2009;2(1):67-78.

2. Lenk M, Berth H, Joraschky P, Petrowski K, Weidner K, Hannig C. Fear of dental treatment--an underrecognized symptom in people with impaired mental health. Dtsch Arztebl Int. 2013;110(3132):517-22.

3. Milgrom P, Newton JT, Boyle C, Heaton LJ, Donaldson N. The effects of dental anxiety and irregular attendance on referral for dental treatment under sedation within the National Health Service in London. Community Dent Oral Epidemiol. 2010;38(5):453-9.

4. Dobros K, Hajto-Bryk J, Wnek A, Zarzecka J, Rzepka D. The level of dental anxiety and dental status in adult patients. J Int Oral Health. 2014;6(3):11-4.

5. Eitner S, Wichmann M, Paulsen A, Holst S. Dental anxiety--an epidemiological study on its clinical correlation and effects on oral health. J Oral Rehabil. 2006;33(8):588-93.

6. Kent G. Anxiety, pain and type of dental procedure. Behav Res Ther. 1984;22(5):465-9.

7. Crofts-Barnes NP, Brough E, Wilson KE, Beddis AJ, Girdler NM. Anxiety and quality of life in phobic dental patients. J Dent Res. 2010;89(3):302-6.

8. Crego A, Carrillo-Diaz M, Armfield JM, Romero M. From public mental health to community oral health: the impact of dental anxiety and fear on dental status. Front Public Health. 2014;2:16. 